\title{
Role of general practitioners in care of long term mentally ill patients
}

\author{
Tony Kendrick, Bonnie Sibbald, Tom Burns, Paul Freeling
}

\begin{abstract}
Objective-To assess general practitioners' involvement with long term mentally ill patients and attitudes towards their care.

Design-Postal questionnaire survey.

Setting-General practices in South West Thames region.

Subjects -507 general practitioners, $369(73 \%)$ of whom returned the questionnaire.

Main outcome measures-The number of adult long term mentally ill patients whom general practitioners estimate they have on their lists and general practitioners' willingness to take responsibility for them.
\end{abstract}

Results -110 respondents had noticed an effect of the discharge of adult long term mentally ill patients on their practices. Most (225) respondents estimated that they had 10 or fewer such patients each on their lists. Having higher numbers was significantly associated with practising in Greater London or within three miles of a large mental hospital and having contact with a psychiatrist visiting the practice. 333 general practitioners would agree to share the care of long term mentally ill patients with the psychiatrist by taking responsibility for the patients' physical problems. Only 59 would agree to act as a key worker, 308 preferring the community psychiatric nurse to do it. Only nine had specific practice policies for looking after long term mentally ill patients and 287 agreed that such patients often come to their general practitioner's attention only when there is a crisis.

Conclusions-The uneven distribution of long term mentally ill patients suggests that community psychiatric resources might be better targeted at those practices with higher numbers of such patients. Most general practitioners seem to be receptive to a shared care plan where the consultant takes responsibility for monitoring psychiatric health with the community nurse as key worker. The lack of practice policies for reviewing the care of long term mentally ill patients must limit general practitioners' ability to prevent crises developing in their care.

Departments of General George's Hospital Medical School, London

Tony Kendrick, MRCGP, Mental Health Foundation research fellow

Bonnie Sibbald, PHD, senior research scientist

Tom Burns, MD, consultant psychiatrist

Paul Freeling, FRCGP, professor of general practice

Correspondence and requests for reprints to: Dr Tony Kendrick, Department of General Practice, St George's Hospital Medical School, London SW 17 0RE.

BMF 1991;302:508-10

\section{Introduction}

Since the 1950s about 80000 psychiatric beds in England have been closed, and a further 15000 closures are planned. ${ }^{1}$ Patients who once would have been kept in hospital are now much more likely to be discharged. An increasing number of long term mentally ill patients are therefore living outside institutions.

The capacity of general practitioners to provide primary medical care to mentally disabled people is seen as crucial to making community care work. ${ }^{2}$ Their role, however, is often unclear, and the lack of participation by general practitioners in planning community care is a cause for concern. ${ }^{3}$

Coincident with the move to community care, there has been an increase in the number of psychiatrists who treat patients in general practice settings ${ }^{4}$ including patients with both psychotic and chronic disorders. ${ }^{56}$ This may allow specialist and general practitioner to work together for their mutual advantage. ${ }^{78}$ Alternatively, general practitioners may relinquish responsibility for long term mentally ill patients to the community psychiatric team.

We investigated general practitioners' perceptions of their role in the care of long term mentally ill patients.

\section{Method}

A questionnaire was sent to every third general practitioner on the family health services authorities' lists for the South West Thames region. Two weeks after the first mailing non-respondents were sent a second questionnaire. Those who did not respond to the second mailing were reminded by telephone two weeks later.

The questionnaire asked whether the general practitioners had noticed an effect of the discharge of long term mentally ill patients on their practices and asked them to estimate the number of such patients they each had on their patient lists using the five categories $0-5,6-10,11-15, \geqslant 16$, and "don't know." The surgery address was used to determine whether the general practitioner practised within the boundaries of Greater London or within three miles of a large mental hospital, or both. Three miles was chosen as a rough radius for a general practitioner's practice area.

The questionnaire also asked whether community psychiatric nurses, social workers, psychologists, or consultant psychiatrists visited the practice to see patients or meet the general practitioners, or both. The general practitioner's experience in hospital psychiatric posts, details of the size of the list, and numbers of doctors in the practice were requested.

Attitudes towards the care of long term mentally ill patients were assessed by using a series of statements to which the general practitioners were asked to respond on a four point scale of "strongly agree," "agree," "disagree," or "strongly disagree." Eight of these statements concerned clinical responsibility for long term mentally ill patients and how care should be shared between psychiatrists and general practitioners for both physical and mental health. Three statements concerned the key worker. Finally, six statements highlighted potential difficulties presented by long term mentally ill patients in general practice.

Long term mentally ill patients were defined as "a group which includes patients with chronic schizophrenia or other psychosis, severe personality disorder, or severe neurosis, and who, by definition, require long term supervision." Our questionnaire was confined to the adult long term mentally ill; we excluded mentally impaired elderly and mentally handicapped patients. A key worker was defined as "the person identified as the point of first contact for a 
patient, maintaining a central therapeutic relationship, assessing the person's needs and the needs of their carers, and acting to ensure the necessary help is received from the various statutory and voluntary bodies involved."

The significance of association between pairs of variables was assessed using the $\chi^{2}$ test or unpaired $t$ test.

\section{Results}

The questionnaire was sent to 523 general practitioners at the addresses given on the family health services authorities' lists; 16 were subsequently found to have retired or moved away from their practices. Of the remaining 507, 369 (73\%) replied. These 369 included 25 single handed practitioners, 34 who described themselves as part timers, and 16 trainees. About half (194) of the respondents were in group practices of three, four, or five partners. The average size of each doctor's list was 2010 patients.

Involvement with long term mentally ill patients-One hundred and ten respondents had noticed an effect of the discharge from hospital of long term mentally ill patients on their practices, 79 specifically mentioning an increase in workload. Table I shows the number of long term mentally ill patients that general practitioners estimated they had on their lists. Two hundred and eighteen respondents had a community psychiatric nurse visiting their practice, 138 a visiting consulting psychiatrist, 103 a visiting social worker, and 69 a visiting clinical psychologist. Eighty respondents had experience of working in a hospital psychiatric post, and six were currently working part time in psychiatry.

TABLE I - Estimated numbers of long term mentally ill patients on each general practitioner's list

\begin{tabular}{lccccc}
\hline No of long term patients: & $0-5$ & $6-10$ & $11-15$ & $\geqslant 16$ & Don't know \\
No of general practitioners: & 102 & 123 & 45 & 56 & 43
\end{tabular}

TABLE II - Who general practitioners think should be responsible for overall and physical care of long term mentally ill patients, who should be the key worker, and what problems these patients present

\begin{tabular}{|c|c|c|c|}
\hline \multirow[b]{2}{*}{$\begin{array}{l}\text { Long term mentally ill patients } \\
\text { discharged into the community }\end{array}$} & \multicolumn{3}{|c|}{ Response } \\
\hline & Agree or strongly agree & $\begin{array}{l}\text { Disagree or strongly } \\
\text { disagree }\end{array}$ & No response \\
\hline 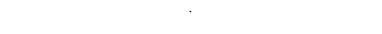 & Overall care & & \\
\hline $\begin{array}{l}\text { Should be primary responsibility of } \\
\text { psychiatric team }\end{array}$ & 301 & 61 & 7 \\
\hline $\begin{array}{l}\text { Should have care organised by general } \\
\text { practitioner with psychiatric back up } \\
\text { as necessary }\end{array}$ & 151 & 207 & 11 \\
\hline $\begin{array}{l}\text { Should have care shared between the } \\
\text { psychiatrist and general practitioner }\end{array}$ & 333 & 31 & 5 \\
\hline $\begin{array}{l}\text { Should be monitored for relapse } \\
\text { by psychiatrist }\end{array}$ & 261 & 93 & 15 \\
\hline $\begin{array}{l}\text { Should be monitored for relapse by } \\
\text { general practitioner }\end{array}$ & 178 & 178 & 13 \\
\hline & Physical care & & \\
\hline $\begin{array}{l}\text { Should be screened for physical } \\
\text { problems by psychiatrist }\end{array}$ & 138 & 224 & 7 \\
\hline $\begin{array}{l}\text { Should be screened for physical } \\
\text { problems by general practitioner }\end{array}$ & 287 & 71 & 11 \\
\hline $\begin{array}{l}\text { Should have their physical problems } \\
\text { managed by general practitioner }\end{array}$ & 343 & 19 & 7 \\
\hline & Key worker & & \\
\hline $\begin{array}{l}\text { Should rely on the community } \\
\text { psychiatric nurse as key worker }\end{array}$ & 308 & 48 & 13 \\
\hline Should rely on social worker as & & & \\
\hline key worker & 160 & 195 & 14 \\
\hline $\begin{array}{l}\text { Should rely on general practitioner as } \\
\text { key worker }\end{array}$ & 59 & 300 & 10 \\
\hline & Problems & & \\
\hline $\begin{array}{l}\text { Pose communication problems between } \\
\text { doctor and patient }\end{array}$ & 235 & 117 & 17 \\
\hline Create lot of work for practice & 250 & 104 & 15 \\
\hline $\begin{array}{l}\text { Rarely cause difficulties for their } \\
\text { families or other carers }\end{array}$ & 38 & 327 & 4 \\
\hline $\begin{array}{l}\text { Often come to attention of their general } \\
\text { practitioner only when there is crisis }\end{array}$ & 287 & 75 & 7 \\
\hline $\begin{array}{l}\text { Have poor prognosis whatever is } \\
\text { done for them }\end{array}$ & 145 & 215 & 9 \\
\hline Are better off out of hospital & 189 & 141 & 39 \\
\hline
\end{tabular}

Nine had specific practice policies for managing long term mentally ill patients.

Attitudes towards the care of long term mentally ill patients - There were few responses in the "strongly agree" or "strongly disagree" categories to almost all of the statements on attitudes towards the care of long term mentally ill patients. Responses were therefore grouped together into either "agree or strongly agree" or "disagree or strongly disagree" (table II). Most of the general practitioners preferred the patients to remain the prime clinical responsibility of the psychiatrist, although shared care was agreeable to most. Most were, however, willing to be responsible for detecting and managing the physical problems of the patients. The community psychiatric nurse was the preferred key worker; few agreed that the general practitioner should have this role. Most of the respondents thought that long term mentally ill patients posed many problems for a practice. Half of the general practitioners, however, considered these patients to be better off out of hospital, and over half disagreed that they had a poor prognosis whatever was done for them.

Numbers of long term mentally ill patients - The higher the estimated number of long term mentally ill patients the more likely was a general practitioner to be practising in Greater London $\left(\chi^{2}=9 \cdot 9, \mathrm{df}=3, \mathrm{p}=0 \cdot 02\right)$, to be located within three miles of a large mental hospital $\left(\chi^{2}=9 \cdot 8, \mathrm{df}=3, \mathrm{p}=0.02\right)$, to have previous experience in a hospital psychiatry post $\left(\chi^{2}=10 \cdot 6, \mathrm{df}=\right.$ $3, p=0.01$ ), and to have contact with a psychiatrist visiting the practice to see patients or meet the general practitioners $\left(\chi^{2}=8 \cdot 7, \mathrm{df}=3, \mathrm{p}=0.03\right)$.

There were no significant associations between the high numbers of long term mentally ill patients and having community psychiatric nurses, social workers, or psychologists visiting the practice. Nor was there any significant association between size of the list and estimated numbers of long term mentally ill patients.

\section{Discussion}

There are several limitations to this study that must be considered when interpreting and extrapolating the findings. Firstly, although the response rate of $73 \%$ was good, the non-responders might have been less optimistic about the care of long term mentally ill patients in the community and less willing to participate in their care. We may therefore be overestimating the positive attitudes of general practitioners towards these patients. Secondly, our sample of general practitioners was taken from the South West Thames region, and the results may not apply to general practitioners in other regions. The definition of the long term mentally ill patient was deliberately broad, allowing the general practitioners to include a wide variety of patients whose precise clinical characteristics are unknown at present. Finally, the responses to the attitude statements were only statements of intent and may not predict what the general practitioners would actually do in practice.

Very few practices keep registers of long term mentally ill patients, and the general practitioners' estimates of their numbers may have been inaccurate. Sixty one per cent of respondents estimated that they had 10 or fewer long term mentally ill patients, which is $0.5 \%$ or less of their patients. Prospective surveys of primary care patients found that about $7 \%$ had mental disorders lasting longer than a year, ${ }^{910}$ of which just under a quarter had serious disability because of their illness. ${ }^{10}$ This would suggest a proportion of long term mentally ill patients of just under $2 \%$, which is considerably higher than the numbers identified by most general practitioners in our study. If the prospective studies dealt with comparable patient populations the general practitioners might have underestimated 
the numbers of long term mentally ill patients. Such patients are often withdrawn, inactive, and slow to complain. Without practice registers of their long term mentally ill patients general practitioners may be unaware of their health needs or even their existence.

From 1980 to 1989 the number of inpatient beds for mentally ill patients in the South West Thames region fell by just over 3000 . (South West Thames Regional Health Authority inpatient statistics, 1980-9.) This is an average of only two beds for each general practitioner in the region. This survey, however, suggests that the distribution of long term mentally ill patients is far from uniform.

It is not surprising that general practitioners with higher estimated numbers of long term mentally ill patients are more likely to be practising in London, given the known tendency for such patients to drift towards inner cities. The association of higher estimated numbers of patients with proximity to a large mental hospital and contact with a visiting psychiatrist may arise because consultants placing former long stay patients recommend them to the local general practitioners with whom they have personal contact. Alternatively, these general practitioners, who are also more likely to have worked in hospital psychiatry posts, may have identified more long term mentally ill patients and encouraged local consultants to come into their practices to help them to cope.

The lack of association between having higher estimated numbers of long term mentally ill patients and having community psychiatric nurses, social workers, or psychologists working on site is cause for concern. Service planners at district level should perhaps consider targeting practices with more long term mentally ill patients for such resources.

The Royal College of Psychiatrists recommends that consultants should keep responsibility for discharged patients, delegating care to a named key worker and discharging them to the care of their general practitioner only when aftercare is no longer necessary. ${ }^{11}$ The Royal College of General Practitioners, however, has emphasised that general practitioners are responsible under their terms of service for the continuing care of patients registered with them. ${ }^{12}$ Strathdee found that general practitioners participating in liaison-attachment schemes with psychiatrists welcomed assessment and short term treatment by the specialist, but did not regard long term takeover of cases as optimum use of the psychiatrist's time. ${ }^{8}$ Our findings suggest that general practitioners favour a shared care model for long term mentally ill patients, with the community psychiatric nurse as key worker and the general practitioner responsible for the patient's physical problems. This is important as long term mentally ill patients have considerable physical ill health, of which a proportion goes unrecognised by psychiatrists. ${ }^{13}$

Our survey has shown an almost complete lack of specific practice policies for the care of long term mentally ill patients. This may contribute to the suggested tendency for general practitioners to participate in the care of disabled patients in the community only at times of crisis. ${ }^{14}$ Whether instituting a policy of active regular review will benefit long term mentally ill patients is an important research question yet to be examined.

We thank Pamela Brown-Peterside and Linda McRaeSamuel for help with producing the questionnaires and collecting the data. $\mathrm{T} \mathrm{K}$ was supported by a grant from the Mental Health Foundation.

1 Thornicroft G. Progress towards DHSS targets for community care. $\mathrm{Br} \mathrm{F}$ Psychiatry 1988;153:257-8.

2 Shepherd $M$. Primary care of patients with mental disorder in the community. $B M 7$ 1989;299:666-9.

3 Groves T. After the asylums. The local picture. BMF 1990;300:1128-30.

4 Strathdee G, Williams P. A survey of psychiatrists in primary care: the silent growth of a new service. $\mathcal{R} R$ Coll Gen Pract 1984;34:615-8.

5 Brown RMA, Strathdee G, Christie-Brown JRW, Robinson PH. A comparison of referrals to primary care and hospital outpatient clinics. Br $\mathcal{F}$ Psychiatry 1988;153:168-73.

6 Tyrer P. Psychiatric clinics in general practice: an extension of community care. Br F Psychiatry 1984;145:9-14.

Mitchell ARK. Psychiatrists in primary health care settings. Br f Psychiatry 1985;147:371-9.

8 Strathdee G. Psychiatrists in primary care: the general practitioner viewpoint. Fam Pract 1988;5:111-5.

9 Shepherd M, Cooper B, Brown AC, Kalton G. Psychiatric illness in general practice. London: Oxford University Press, 1966.

10 Regier DA, Burke JD, Manderscheid RW, Burns BJ. The chronically mentally ill in primary care. Psychol Med 1985;15:265-73.

11 Royal College of Psychiatrists. Good practice in discharge and aftercare procedures for patients discharged from inpatient treatment. London: Royal College of Psychiatrists, 1989.

12 Royal College of General Practitioners. Comments on the working party report on good practice in discharge and aftercare procedures for patients discharged from inpatient treatment. London: Royal College of General Practitioners, 1990. 3 Brugha TS, Wing JK, Smith BL. Physical health of the long-term mentally ill in the community: is there unmet need? Br f Psychiatry 1989;155:777-81. 4 Murphy E. Community care. I. problems. BMF 1987;295:1505-8.

(Accepted 24 fanuary 1991)

\section{MATERIA INDOMEDICA}

\section{Funny rib}

Clinical medicine is not just serious, brain wrecking work but has a sprinkling of humour too. On occasions one comes across instances that tickle for a long, long time.

As a resident in neurology, I recall a patient with muscle weakness. I was measuring the circumference of the thigh with an inch tape. I was taken aback when the patient sat up and said, "Doctor, could I have it a little looser at the thighs - I prefer baggies." At first I could not understand what he meant but then I realised and could not but laugh. The patient thought that I was taking measurements for making his hospital dress.

Another humorous incident, though a little painful, happened when a senior resident in endocrinology after the evening round left a note for his junior. The note was: "Sleeping P/R every 1 hour." Next morning the patient was found agitated and upset. The cause became clear when he revealed that, though his problem was his thyroid gland, he had been subjected to at least six per rectal (P/R) examinations during the night. Needless to add that the junior resident was not seen around for the next seven days.

Proctoscopy is a particularly painful procedure but essential and done routinely on several patients in a day. As a means to reduce the pain and anxiety our professor of surgery would keep the patient engaged in conversation while doing the procedure. On one such occasion he asked,
"Do you smoke?" Prompt came the answer, "Is the smoke still coming out, sir?" All the students burst into laughter.

At a conference the professor of ophthalmology was being honoured for one of his original contributions. On the stage in the background was a huge cut out of an eye and in the pupil was a photograph of this esteemed professor. As he came up on to the stage to a standing ovation he saw that cut out and his first sentence of an otherwise long technical speech made everyone burst into laughter. He began by pointing towards the cut out and saying, "Thank God I am not a gynaecologist."

Another episode that I cannot forget happened when our professor of medicine was taking an undergraduate class. He was jotting down the presenting complaints of the patient on the blackboard. He had written, "Anorexia, nausea, and vomitting -6 months." One of the students pointed out that vomiting was spelt with one " $t$ " and not two as he had written. Not to be cowed the professor called his senior resident to ask him whether vomiting was spelt as vomiting or vomitting. The senior resident saw the blackboard and realised the situation. His answer made even the professor smile. He said, "Sir, actually it depends; if the vomitings are few then it has only one ' $\mathrm{t}$ ' but as in this case the patient is profusely vomiting it is not wrong to use two ' $t$ 's." Such wit, though rare, gives that little touch that keeps us all going. - SANJIV SAXENA 